\title{
Effects of vasopressin on multiple fixed-ratio fixed-interval schedules of reinforcement
}

\author{
STEVEN L. COHEN \\ Bloomsburg University, Bloomsburg, Pennsylvania
}

and

\author{
MARTHA KNIGHT, CAROL A. TAMMINGA, and THOMAS N. CHASE \\ National Institute of Neurological and Communicative Disorders and Stroke, National Institutes of Health, \\ Bethesda, Maryland
}

\begin{abstract}
The effect of arginine- and des-glycinamide arginine vasopressin on steady-state operant responding was examined. Rats were trained to press a lever for food under a multiple fixed-interval 4-min fixed-ratio 30 schedule of reinforcement. Arg vasopressin (0.5 to $100 \mu \mathrm{g} / \mathrm{kg}$, subcutaneous) produced a dose-dependent decrease in response rate, but des-glycinamide arginine vasopressin $(0.5$ to $100 \mu \mathrm{g} / \mathrm{kg}$, subcutaneous) had no effect. Neither peptide significantly altered fixed-interval response patterning. These data suggest that vasopressin's behavioral effects should be viewed in light of its aversive peripheral actions.
\end{abstract}

Exogenous vasopressin has varied effects on behavior. Arginine (AVP) and lysine (LVP) vasopressin (0.1 to $3 \mu \mathrm{g} / \mathrm{kg}$ ) retard the extinction of active avoidance responding in rats (deWied, 1971; Schulz, Kovács, \& Telegdy, 1974), and increase the latency to reenter the shock compartment in a one-trial passive avoidance test (Ader \& deWied, 1972; Bohus, Ader, \& deWied, 1972; Kovács, Vécsei, \& Telegdy, 1978). Other effects include reductions in electroconvulsive shock-, $\mathrm{CO}_{2^{-}}$, and diethyldithiocarbamate-induced retrograde amnesia (Asin, 1980; Pfeifer \& Bookin, 1978; Rigter, van Riezen, \& deWied, 1974); poor avoidance learning by vasopressin-deficient Brattleboro rats (Bohus, van Wimersma Greidanus, \& deWied, 1975); and retardation of passive avoidance responding by intraventricular injections of antivasopressin serum (van Wimersma Greidanus \& deWied, 1976). These data have led to the hypothesis that vasopressin is linked to memory consolidation and retrieval mechanisms. Some investigators have suggested that vasopressin might improve human cognitive functions (Beckwith et al., 1982).

One limitation of research involving vasopressin is that most experiments employ aversive conditioning techniques (i.e., passive and active avoidance). Recently, investigators (Alliot \& Alexinsky, 1982; Messing \& Sparber, 1983; Sahgal, 1983) have recognized the need to examine appetitively motivated behaviors before a general theory of vasopressin's effects can be formulated. Unfortunately, research on the effects of vasopressin in posi-

We thank William Krivoy and John M. Stewart for their assistance in obtaining and testing AVP and DG-AVP. Please address correspondence regarding this paper to: S. L. Cohen, Department of Psychology, Bloomsburg University, Bloomsburg, PA 17815. tive reinforcement paradigms, such as discriminations (Alliot \& Alexinsky, 1982; Bohus, 1977; Hostetter, Jubb, \& Kozlowski, 1977; Sara, Barnett, \& Toussaint, 1982), autoshaping (Alliot \& Alexinsky, 1982; Pfeifer \& Bookin, 1978; Sahgal, 1983), and extinction of maze running (Garrud, Gray, \& deWied, 1974), have not been as consistent or robust as those using aversive conditioning paradigms, and it is difficult to draw general conclusions from these data.

An understanding of the varied effects of vasopressin on complex appetitively-motivated processes, such as acquisition, discrimination, and extinction, may be facilitated by studies of its effects on simpler steady-state operant responding. Increases or decreases in ongoing response rate or alteration in response patterning following vasopressin might help in the interpretation of existing data. For example, if vasopressin has a generalized excitatory effect (as might be predicted from its retardation of avoidance extinction), then an increase in response rate might be expected. An overall decrease in response rate would be consistent with previous experiments reporting retardation of response acquisition (Alliot \& Alexinsky, 1982; Sahgal, 1983) and decreases in locomotion (Ettenberg, van Der Kooy, Le Moal, Koob, \& Bloom, 1983; Sahgal, 1983) following vasopressin.

The present study was an attempt to collect data on the effects of vasopressin on schedule-controlled responding. Rats were trained to press a lever for food under a multiple fixed-interval (FI) fixed-ratio (FR) schedule of reinforcement. After response rate stabilized, AVP and desglycinamide arginine vasopressin (DG-AVP) - a vasopressin analog lacking antidiuretic and pressor activity-were administered across a large dose range, and response rates and patterning were analyzed. 


\section{METHODS}

\section{Subjects}

Five male Sprague-Dawley rats (Taconic Farms) were maintained at $80 \%$ free-feeding (290-315 g) body weight. Rats had previous leverpressing experience in a conditional discrimination experiment but were drug naive. Rats were individually caged, had free access to water, and were housed on a 12:12 hr light/dark cycle with light on at 7:00 a.m.

\begin{abstract}
Apparatus
A single-lever operant conditioning chamber for rats (Coulbourn Instruments, model E10-10) was housed within a sound-attenuated cubicle. The response lever was located on the right side, and the food trough was located in the center of the work panel. A shielded (shield facing down) 28-V white houselight was positioned directly above the food trough and an unshielded $28-\mathrm{V}$ white houselight was centered at the top of the work panel. An electromechanical relay and Sonalert were located behind the work panel. Solid state circuitry controlled experimental contingencies.
\end{abstract}

\section{Procedure}

Because of prior lever-pressing experience, rats were placed directly on a multiple (mult) FR 5 FI 16-sec schedule of reinforcement. In the first stimulus component (the electromechanical relay clicking at a rate of $2 / \mathrm{sec}$ ), a 45-mg Noyes food pellet was delivered after the fifth lever press (i.e., FR 5), and in the second stimulus component (the Sonalert tone) food was delivered for the first lever press after $16 \mathrm{sec}$ timed from stimulus onset (i.e., FI 16-sec). During food delivery, the houselight above the food trough was turned on for $4 \mathrm{sec}$, the component stimulus stayed on, and responses had no scheduled effects. The FR and FI components alternated after each food presentation. Sessions began with the FR component and ended after a total of 60 components. The houselight at the top of the work panel remained on during the entire session.

Over a period of 22 sessions, the FR and FI schedules were gradually increased to mult FR 30 FI 4-min. Sessions ended after a total of 30 components or $85 \mathrm{~min}$, whichever came first. If food was not delivered during a component, the component switched automatically after 6 min. If this switch occurred during an FI 4-min component, the FI was reset for the next FI component. In the FR 30 component, accrued responses carried over to the next FR component.

$\mathrm{Arg}^{8}$-vasopressin (AVP), and $\mathrm{Arg}^{8}$, des-glycinamide ${ }^{9}$-vasopressin (DG-AVP) (California Medicinal Chemistry Corp.) were dissolved in physiological saline and used immediately. The purity of vasopressin was assured by high performance liquid chromatography and amino acid analysis. Biological activity was tested in the rat uterus assay. Injections began after 15 sessions of mult FR 30 FI 4-min training. Injections were given subcutaneously on the back of the neck $20 \mathrm{~min}$ before a session in a volume of $1-\mathrm{ml} / \mathrm{kg}$ body weight. Sessions were conducted Monday through Friday with injections occurring on Tuesday and Friday. AVP was given in the following sequence: 0 (saline), $0.5,5,10$, $100 \mu \mathrm{g} / \mathrm{kg}$ (ascending series) and 100,10,5,1, 0.5, $0 \mu \mathrm{g} / \mathrm{kg}$ (descending series). DG-AVP was then given in the following sequence: 100 , $10,5,1,0.5 \mu \mathrm{g} / \mathrm{kg}$.

\section{RESULTS}

Total responses in both FI and FR components were recorded. Response rates were computed for each cornponent and are presented in Figure 1 for both ascending and descending injection series. Response rates from Thursday (no injection) sessions were used as control (C) data. Overall baseline response rate was about twice as high in the FR compared to the FI component, demonstrating good stimulus control. AVP produced a dosedependent decrease in response rate (Figure 1). This decrease was confirmed by a one-factor repeated-measures ANOVA that included control, saline, and AVP sessions $[F(5,20)=15.0, p<.01$ and $F(6,24)=23.6$,

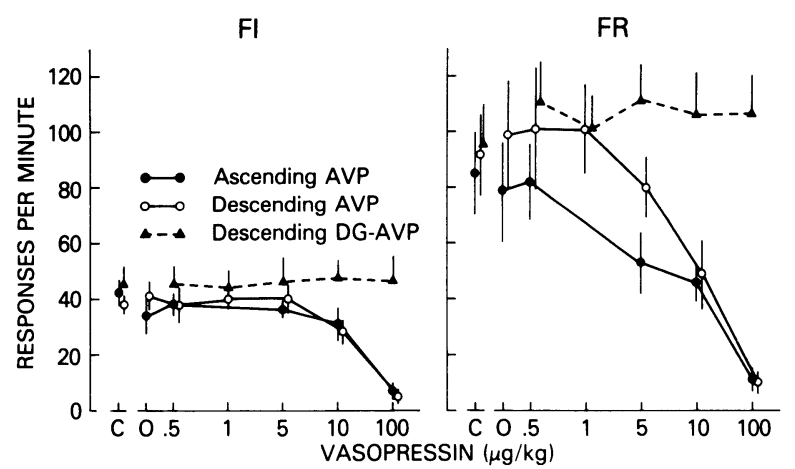

Figure 1. Response rates during the fixed-interval 4-min (FI) and fixed-ratio 30 (FR) components of the multiple schedule. $C$ represents response rates during noninjection control sessions. Data are means and standard errors for five rats during ascending and descending dose injection of arginine- (AVP) and des-glycinamide arginine (DGAVP) vasopressin.

$\mathrm{p}<.01$ for ascending and descending FI components respectively; $F(5,20)=12.8, p<.01$ and $F(6,24)=$ $17.7, \mathrm{p}<.01$ for ascending and descending FR components respectively]. In the FI component, response rate was unaffected from 0 to $5 \mu \mathrm{g} / \mathrm{kg}$, decreased at $10 \mu \mathrm{g} / \mathrm{kg}$, and substantially suppressed at $100 \mu \mathrm{g} / \mathrm{kg}$. The FR component was more sensitive than the FI component to the effects of AVP in that response suppression was observed at 5 as well as 10 and $100 \mu \mathrm{g} / \mathrm{kg}$. Similar data were observed in the ascending and descending injection series, confirming the reliability of the data. DG-AVP did not significantly affect response rate in either the $\mathrm{FI}[\mathrm{F}(5,20)$ $=0.32]$, or the $F R[F(5,20)=2.56]$, components.

Responses in each of eight $30-\mathrm{sec}$ periods of the FI 4-min schedule were recorded. The index of curvature was determined from these data (Figure 2). The index of curvature is a statistic that describes the degree of response patterning under FI schedules and is thus a measure of temporal discrimination (Fry, Kelleher, \& Cook, 1960). A value of 0 indicates a constant response rate across the

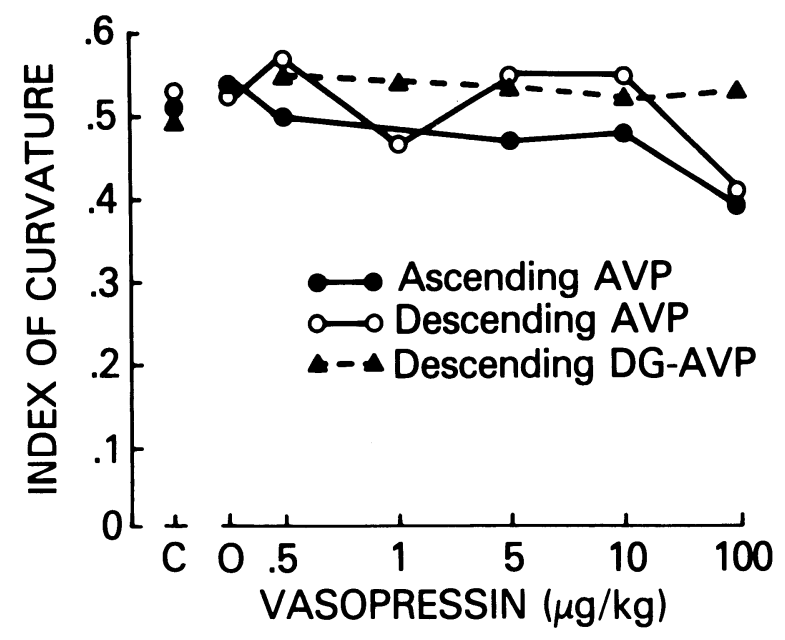

Figure 2. Index of curvature during the FI 4-min component of the multiple schedule. Data are means for all rats. 
FI, while large values indicate greater curvature. A value of 0.88 , for example, would mean that all responses in the FI 4-min schedule were emitted during the last $30 \mathrm{sec}$ of the FI.

The FI 4-min schedule generated a high degree of response curvature. Response rate was very low in early portions of the FI and increased toward the end of the FI. Despite the changes in overall response rate following AVP, there was a small effect on response patterning (Figure 2). The small decrease in curvature at $100 \mu \mathrm{g} / \mathrm{kg}$ AVP might be expected, because very low response rates make the index a less reliable measure. The decrease in curvature was not significant for the AVP ascending injection series $[F(5,18)=2.72]$. (A Yates' correction procedure for missing values was used, because data from one rat were not used due to extremely low response rates following $100 \mu \mathrm{g} / \mathrm{kg}$.) There was significant decrease in curvature in the AVP descending series $[\mathrm{F}(6,24)=5.41$, $\mathrm{p}<.01]$. DG-AVP did not affect index of curvature $[F(5,20)=1.1]$. In the FR component, typical FR response patterning was observed across conditions: a pause after reinforcement followed by a high constant response rate.

\section{DISCUSSION}

Systemic administration of AVP produced a dose-dependent decrease in food-reinforced operant responding. Under the FI schedule, the decrease was not apparent until a relatively high dose of AVP $(10 \mu \mathrm{g} / \mathrm{kg})$ was used. Under the FR schedule, suppression was evident at $5 \mu \mathrm{g} / \mathrm{kg}$. These data are consistent with Alliot and Alexinsky (1982) and Sahgal (1983) who reported that vasopressin retards food-reinforced lever pressing in rats, and the data indicate that response suppression is not limited to responding maintained by continuous reinforcement schedules.

Vasopressin has been shown to consistently retard the extinction of active avoidance responding when given from $15 \mathrm{~min}$ to several hours before extinction testing (Bohus et al., 1972; deWied, 1971; Schulz et al., 1974). This finding could be explained if vasopressin caused a generalized increase in activity. An excitatory effect could be expected to result in persistent avoidance responding and increased operant response rate. This explanation of persistent avoidance responding received no support from the present data. There was no evidence of increased responding at any dose of AVP or DG-AVP.

It has been reported (Dorsa \& van Ree, 1979; van Ree \& deWied, 1977a, 1977b) that DG-AVP suppresses lever pressing in rats selfadministering heroin and reinforcing electrical brain stimulation. These investigators have argued that vasopressin might decrease the value of reinforcing stimuli by interacting with the neural substrates of reward. In the present study, DG-AVP had no effect on responding. Mello and Mendelson (1979) also showed that 25 and $125 \mu \mathrm{g} / \mathrm{kg}$ DG-AVP injected immediately before the test session had no effect on food- or morphinereinforced operant responding in monkeys. It is difficult to isolate the variables that account for these discrepant findings, although it appears unlikely to be species, type of reinforcer, or drug dose. The present data do not support the view that DG-AVP affects the reinforcing properties of food.

Vasopressin has been shown to have weak and inconsistent effects on visual and spatial discrimination tasks (Alliot \& Alexinsky, 1982; Bohus, 1977; Hostetter et al., 1977; Sara et al., 1982). Meck (1983) recently showed that vasopressin increases the rate of acquisition of a temporal discrimination in a two-lever psychophysical procedure. Responding under an FI schedule may be considered a type of temporal discrimination with responding limited to the end of the interval indicative of good discriminative performance. In the present study, AVP or
DG-AVP did not affect response patterning (i.e., index of curvature) under the FI 4-min schedule and provides no support that vasopressin improves temporal discrimination performance.

The disruption of lever pressing after AVP most likely resulted from a powerful pressor response. DG-AVP is devoid of this peripheral action and did not affect responding. It has been shown (LeMoal et al., 1981) that an AVP antagonist tha: blocks the pressor response concomitantly eliminates increased resistance to extinction in avoidance responding typically seen after AVP administration. The effects of this pressor response was clearly evident in the open field. After this experiment terminated, fond-deprived rats were given $100 \mu \mathrm{g} / \mathrm{kg} \mathrm{AVP}$ and observed for $15 \mathrm{~min}$ in an open field with a cup of $45-\mathrm{mg}$ Noyes food pellets. At this high dose, rats had great difficulty walking and showed a significant reduction in activity. It is unlikely that AVP affected hunger because even ataxic rats went directly to the food cup and consumed pellets although they had difficulty chewing and swallowing.

\section{REFERENCES}

ADER, R., \& DEWIED, D. (1972). Effects of lysine vasopressin on passive avoidance learning. Psychonomic Science, 29, 46-48.

Alliot, J., \& AlEXINSKY, T. (1982). Effects of post-trial vasopressin injections on appetitively motivated learning in rats. Physiology \& Behavior, 28, 525-530.

Asin, K. E. (1980). Lysine vasopressin attenuation of diethyldithiocarbamate-induced amnesia. Pharmacology Biochemistry \& Behavior, 12, 343-346.

Beckwith, B. E., Petros, T., Kanaan-Beckwith, S., Couk, D. I., HAUG, R. J., \& RYAN, C. (1982). Vasopressin analog (DDAVP) facilitates concept learning in human males. Peptides, 3, 627-630.

BoHUs, B. (1977). Effect of desglycinamide-lysine vasopressin (DGLVP) on sexually motivated T-maze behavior of the male rate. Hormones \& Behavior, 8, 52-61.

BoHus, B., AdER, R., \& DEWIED, D. (1972). Effects of vasopressin on active and passive avoidance behavior. Hormones \& Behavior, 3 , 191-197.

Bohus, B., van Wimersma Greidanus, T. B., \& DeWied, D. (1975). Behavioral and endocrine responses of rats with hereditary hypothalamic diabetes insipidus (Brattleboro strain). Physiology \& Behavior, 14, 609-615.

DEWIED, D. (1971). Long term effect of vasopressin on the maintenance of a conditioned avoidance response in rats. Nature, 232, 58-60.

DoRSA, D. M., \& VAN ReE, J. M. (1979). Modulation of substantia nigra self-stimulation by neuropeptides related to neurohypophyseal hormones. Brain Research, 172, 367-371.

Ettenberg, A., van Der Kooy, D., Le Moal, M., Koob, G. F., \& Bloom, F. E. (1983). Can aversive properties of (peripherallyinjected) vasopressin account for its putative role in memory? Behavioral Brain Research, 7, 331-350.

Fry, W., Kelleher, R. T., \& CoOK, L. A. (1960). A mathematical index of performance on fixed-interval schedules of reinforcement. Journal of the Experimental Analysis of Behavior, 3, 193-199.

GARRUD, P., GRAY, J. A., \& DEWIED, D. (1974). Pituitary-adrenal hormones and extinction of rewarded behavior in the rat. Physiology \& Behavior, 12, 109-119.

Hostetter, G., Jubb, S. L., \& Kozlowski, G. P. (1977). Vasopressin affects the behavior of rats in a positively-rewarded discrimination task. Life Sciences, 21, 1,323-1,327.

Kovács, G. L., Vécsei, L., \& Telegdy, G. (1978). Opposite action of oxytocin to vasopressin in passive avoidance behavior in rats. Physiology \& Behavior, 20, 801-802.

LeMoal, M., KoOB, G. F., Koda, L. Y., Bloom, F. E., Manning, M., SAWYER, W. H., \& Rivier, J. (1981). Vasopressor receptor antagonist prevents behavioural effects of vasopressin. Nature, 291, 491-493.

MECK, W. H. (1983). Selective adjustment of the speed of internal clock and memory processes. Journal of Experimental Psychology: Animal Behavior Processes, 9, 171-201.

Mello, N. K., \& MENDELSON, J. H. (1979). Effects of the neuropeptide 
DG-AVP on morphine and food self-administration by dependent rhesus monkey. Pharmacology Biochemistry \& Behavior, 10, 415-419.

Messing, R. B., \& SPARBER, S. B. (1983). Des-gly-vasopressin improves acquisition and slows extinction of autoshaped behavior. European Journal of Pharmacology, 89, 43-51.

PFeIFER, W. D., \& BookIN, H. B. (1978). Vasopressin antagonizes retrograde amnesia in rats following electroconvulsive shock. Pharmacology Biochemistry \& Behavior, 9, 261-263.

RigTer, H., VAN Riezen, H., \& DEWIED, D. (1974). The effects of ACTH- and vasopressin-analogues on $\mathrm{CO}_{2}$-induced retrograde amnesia in rats. Physiology \& Behavior, 13, 381-388.

SAHGAL, A. (1983). Vasopressin retards the acquisition of positively reinforced lever pressing in homozygous Brattleboro rats. Regulatory Peptides, 5, 317-326.

SARA, S. J., BARNetT, J., \& Toussaint, P. (1982). Vasopressin ac- celerates appetitive discrimination learning and impairs its reversal. Behavioral Processes, 7, 157-167.

Schulz, H., Kovács, G. L., \& Telegdy, G. (1974). Effect of physiological doses of vasopressin and oxytocin on avoidance and exploratory behavior in rats. Acta Physiologica Academiae Scientiarum Hungaricae, 45, 211-215.

VAN REE, J. M., \& DEWIED, D. (1977a). Modulation of heroin selfadministration by neurohypophyseal principles. European Journal of Pharmacology, 43, 199-202.

VAN REE, J. M., \& DEWIED, D. (1977b). Heroin self-administration is under control of vasopressin. Life Sciences, 21, 315-320.

van Wimersma Greidanus, T. B., \& DeWied, D. (1976). Modulation of passive-avoidance behavior of rats by intracerebroventricular administration of antivasopressin serum. Behavioral Biology, 18, 325-333.

(Manuscript received for publication April 26, 1985.) 